impregnated, but the new exoskeleton is at once too thin and, except immediately after ecdysis, too impermeable to show a clear reaction before that eventual non-specific deposition in all tissues which coincides with the appearance of evident spontaneous oxidation in the solution.

A dopase reaction has been demonstrated in the presumptive melanophores of the recently released young of Asellus, though these cells appear to be very few in number at any one time. Pigmentation develops gradually in these young animals which, like the newly eclosed regenerate, are very conspicuous meanwhile. The relatively late development of the protective coloration, in both, remains an interesting problem.

Fully pigmented non-regenerating limbs fail to give the reaction under the same conditions, the enzyme disappearing with the development of the natural pigment. The latter is readily distinguished from the pigment derived from 'Dopa' by its more golden-brown colour when viewed under the microscope.

Like the polyphenol oxidases of other invertebrates ${ }^{3}$ and of other arthropods ${ }^{8}$, the enzyme is incapable of oxidizing tyrosine itself. With the 'nadi' reagent a strong reaction is given by the muscles and by the nuclei of most tissues, but none of the free cells gives a clear reaction.

A similar specific reaction, with deposition of melanin in the presumptive melanophores of a regenerating limb, is, however, obtained with $5: 6$ dihydroxyindole, recently synthesized ${ }^{7}$ in Prof. A. A. Robertson's laboratory, and would seem to lend further support to the view ${ }^{8}$ that this substance is a transitory intermediary in the formation of melanin from 'Dopa'. The details of the reaction in general resemble those for 'Dopa', the muscles and other tissues later becoming melanic ; but there are differences, some of which may be significant. Thus the colour of the pigment passes through purple to black, while 'Dopa' passes through slate-grey (possibly merely a $p H$ difference ${ }^{7}$ ). Secondly, the reaction is much more rapid under the same conditions $(2-10$ min. as compared with $\frac{1}{2}-1 \mathrm{hr}$.). The spontaneous oxidation of the solution is correspondingly more rapid (complete in 2-3 hr. as compared with 2-3 days for pure 'Dopa'). Thirdly, cells containing natural melanin are still capable of specific accumulation of more melanin from $5: 6$ dihydroxyindole. Further, stronger reactions are obtained with exuviæ, and with the 'liver' of the animal, than those due to 'Dopa' (possibly merely a difference in rate of deposition).

I am indebted to Prof. H. S. Raper for the gift of 'Dopa' and for advice, in particular for suggesting that 5:6 dihydroxyindole be tested, and to Prof. A. A. Robertson for the gift of this reagent.

Department of Zoology and

A. E. NEEDHAM

Comparative Anatomy,

University Museum,

Oxford.

May 24.

${ }^{1}$ Baldwin, E., and Beatty, R. A., J. Exp. Biol., 18, 136 (1941).

"Needham, A. E., Quart. J. Micr. Sci., 84, 49 (1942).

${ }^{3}$ Lison, L., "Histochimie Animale" (Paris, 1936).

"Bloch, B., "Das Pigment" in Jadassohn's "Handb. d. Haut. u. Geschlechtskrankheiten", I, i, 434 (1927).

s Needham, J., "Chemical Embryology", 3, 1381 (Cambridge, 1931).

- Dennell, R., Nature, 154, 57 (1944).

'Beer, R. J. S., Clarke, K., Khorana, H. G., and Robertson, A. A., J. Chem. Soc., 2223 (1948).

${ }^{8}$ Raper, H. S., Biochem.J., 21, 89 (1927); Physiol. Rev., 8, 253 (1928).

\section{Rapid Calculation of Standard Deviations}

A GRAPHICAL method, even simpler than that described by Woolf $^{1}$, of carrying out the major calculations in the determination of standard deviations can be suggested.

Suppose it is required to find the square root of the sum of the squares of the values $a, b, c$, etc. Draw $A B$ equal to $a$, and by means of a graduated setsquare mark the point $C$ in a line perpendicular to $A B$ at a distance $B C$ equal to $b$. Place one side of the set-square along $A C$ so that its apex is at $C$, and mark $D$ at a distance from $C$ equal to $c$. Proceed in the same way with the other values. Then $A C=$ $\left(a^{2}+b^{2}\right)^{1 / 2}, A D=\left(a^{2}+b^{2}+c^{2}\right)^{1 / 2}, A E=\left(a^{2}+\right.$ $\left.b^{2}+c^{2}+d^{2}\right)^{1 / 2}$, and so on.

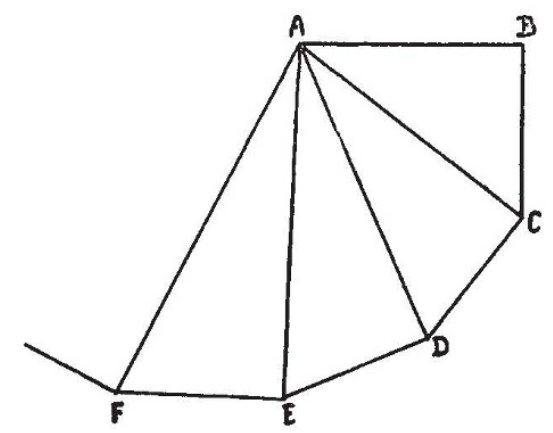

If the number of values is large, the operations can be carried out on, say, ten or twenty values at a time, and the final hypotenuses can be combined in a similar manner, possibly after reducing them to a half or a quarter of their size.

In a modification of the above, it is unnecessary to mark the paper at all except for the initial point $A$. Place the set-square so that one side passes through $A$ and the apex is at $B$, a distance $a$ from $A$. Slide another set-square along the other side $B C$, leaving its apex at $C$, a distance $b$ from $B$. Move the first set-square and place it so that one side passes through $A$ and its apex touches the apex of the second setsquare at $C$. Move the second set-square and slide it along the side $C D$ of the first, etc.

By still another slight modification it is possible to obtain the mean graphically as well as the standard deviation. Let $a, b, c$, etc., be the 'positive' deviations from a value which in general is not the mean, and let $a^{\prime}, b^{\prime}, c^{\prime}$, etc., be the 'negative' deviations. Then in each case carry out the operations indicated in the drawing, but mark the points $A, B, C$, etc., with pins. Attach a piece of cotton to $A$, and simply pass it round the pins marking the figure $A B C D E$..., measure the length in each case, obtain the difference, divide by the number of values, and use the resulting figure to correct the value from which the original deviations were taken. Each of the lengths will be slightly in error because of the curvature of the pins, but with a normal distribution the errors will tend to cancel out when the subtraction is made if the zero value is not far from the mean.

\section{G. S. SмIтH}

Aeronautical Inspection Directorate, Test House,

Harefield, Middlesex. Sept. 6.

${ }^{1}$ Woolf, B., Nature, 164, 360 (1949). 